\title{
Marc Carnel, "Le sang embaumé des roses». Sang et passion dans la poésie amoureuse de Pierre de Ronsard
}

\section{Dario Cecchetti}

\section{(2) OpenEdition}

1 Journals

\section{Edizione digitale}

URL: http://journals.openedition.org/studifrancesi/34527

DOI: 10.4000/studifrancesi.34527

ISSN: 2421-5856

\section{Editore}

Rosenberg \& Sellier

\section{Edizione cartacea}

Data di pubblicazione: 1 novembre 2005

Paginazione: 404-405

ISSN: 0039-2944

\section{Notizia bibliografica digitale}

Dario Cecchetti, «Marc Carnel, «Le sang embaumé des roses». Sang et passion dans la poésie amoureuse de Pierre de Ronsard», Studi Francesi [Online], 146 (XLIX | II) | 2005, online dal 30 novembre 2015, consultato il 18 avril 2021. URL: http://journals.openedition.org/studifrancesi/34527 ; DOI: https:// doi.org/10.4000/studifrancesi.34527

\section{Questo documento è stato generato automaticamente il 18 avril 2021.}

\section{(c)}

Studi Francesi è distribuita con Licenza Creative Commons Attribuzione - Non commerciale - Non opere derivate 4.0 Internazionale. 


\title{
Marc Carnel, «Le sang embaumé des roses». Sang et passion dans la poésie amoureuse de Pierre de Ronsard
}

\author{
Dario Cecchetti
}

\section{NOTIZIA}

MARC CARNEL, «Le sang embaumé des roses». Sang et passion dans la poésie amoureuse de Pierre de Ronsard, Genève, Droz («Travaux d'Humanisme et Renaissance», CCCXCV), 2004, pp. 509.

Si tratta di un ampio e denso studio sul tema e sulla simbologia del sangue nell'opera di Ronsard, in particolare nelle raccolte più propriamente amorose, quali le Amours, le Continuations des Amours, Sur la Mort de Marie, le Amours d'Eurymedon et de Calliree, i Sonets et madrigals pour Astree e i Sonets pour Helene, senza peraltro trascurare le altre raccolte là dove propongono pagine amorose o sviluppano una linea erotica. L'autore analizza, nella scrittura amorosa di Ronsard, i loci connessi al sangue e alle sue alterazioni, mettendo in evidenza «una progressione che, attraverso la topologia del sangue amoureux che li percorre e li modella, parte dal corpo, conduce allo spirito, all'anima e ai fantasmi» (p. 18). Il ricco contributo critico di Marc Carnel si propone pertanto di «indagare l'energia, le patologie e i sogni del sangue nella poesia amorosa di Ronsard, proprio perché questa poesia parla del corpo del poeta, del corpo dell'altra, delle sue seduzioni, dei suoi rifiuti; e perché, colpito dalla violenza dell'innamoramento, il sangue che si infuoca e si esaurisce in una passione senza ritorno finisce col trasformarsi in uno specchio narcisista in cui si fissano le ossessioni del poeta. A differenza della scrittura di numerosi autori contemporanei acquisiti alla mistica, la poesia ronsardiana esalta la sensualità senza pertanto limitarsi alla solo concupiscenza, in quanto Ronsard sa esprimere il desiderio ed anche la trascendenza. Il più delle volte straziato tra queste due esigenze, il poeta innamorato non cessa di proclamare che è condannato a una frustrazione fatale che lo annienta in un desiderio il cui oggetto è 
sempre manchevole» (p. 17). Dal momento che la poesia di Ronsard ripercorre quei meandri del corpo, dello spirito e dell'anima in cui si insinua un malessere, considerato all'epoca come una 'malattia' d'amore presa con la massima serietà sul piano clinico, Carnel non solo ricostruisce la sintomatologia di questa malattia (descritta con le caratteristiche della bile in Cassandre, della pituita in Marie e, in genere, della melanconia), ma ne circoscrive il quadro concettuale medico mediante i testi di Ippocrate, Galeno e Ambroise Paré e il contesto filosofico mediante le opere di Platone, Aristotele, Ficino e Burton, confrontando sempre - secondo un ordine tematico e, per quanto riguarda la scelta dei testi ronsardiani, cronologico - la scrittura di Ronsard con l'intertestualità letteraria, appartenga questa all'antichità classica, al codice petrarchista, ai poeti neolatini o ai contemporanei rinascimentali.

2 Il lavoro è strutturato nelle seguenti parti. Una prima sezione ricostruisce la storia medica del sangue nel Rinascimento, illustrando le teorie che, nei decenni precedenti le scoperte di Harvey nel 1628, definiscono il sangue in rapporto ai tre altri umori. Una seconda sezione studia alla luce delle dottrine neoplatoniche, ampiamente diffuse attraverso l'opera di Marsilio Ficino, alcuni luoghi comuni della lirica amorosa ronsardiana, esplorando in particolare la fisiologia e il significato di quel colpo di fulmine che, grazie al sangue, collega gli occhi al cuore in cui si apre una piaga feconda. La terza sezione si propone di «seguire i cerchi concentrici che si propagano da questa ferita fondatrice», studiando la trasformazione del sangue in veleno. La quarta sezione - a nostro parere estremamente interessante per il materiale che offre per uno studio iconologico e tematico dei testi ronsardiani - esamina le alterazioni mentali che hanno origine dalla crisi provocata dal confondersi di umori avversi, in particolare dalla melanconia che suscita immagini ossessive. Un'ultima sezione studia un immaginario associato al tema del cuore che viene dato, viene preso e strappato nella violenza dei sacrifici (come, per esempio, le immagini connesse al mito di Prometeo). Il metodo seguito, che è quello di fare emergere quella 'polifonia' dei testi ronsardiani elaborata, per riprendere un'espressione cara a Terence Cave, dalla copia, dalla ripetizione e dalla trasformazione delle immagini, offre uno strumento utile allo studioso di Ronsard, per penetrare nel laboratorio del poeta attraverso lo studio degli echi, delle consonanze e delle dissonanze. 